DISTINCTIVE ASSUMED SIMILARITY IN HONESTY-HUMILITY AND OPENNESS

TO EXPERIENCE

Seeing you in me: Moderating role of relationship satisfaction and commitment on assumed similarity in Honesty-Humility and Openness to Experience

\author{
Jie Liu ${ }^{\mathrm{a}}$ \\ Ville-Juhani Ilmarinen ${ }^{\mathrm{b}}$ \\ Christina Lehane ${ }^{\mathrm{c}}$
}

${ }^{\text {a}}$ Faculty of Education, Northeast Normal University. Renmin Street 5268, China.

Email: liujie@nenu.edu.cn.

${ }^{\mathrm{b}}$ Swedish School of Social Science, University of Helsinki. Snellmaninkatu 12, PO

BOX 16, 00014, Finland. Email: ville-juhani.ilmarinen@helsinki.fi

${ }^{c}$ Department of Public Health, Faculty of Health and Medical Sciences, University of

Copenhagen, Denmark. Email: christine.m.lehane@gmail.com

This is the submitted version of the manuscript that has been accepted for publication in Journal of Research in Personality https://doi.org/10.1016/j.jrp.2022.104209

Citation:

Liu, J., Ilmarinen, V. J., \& Lehane, C. (2022). Seeing you in me: Moderating role of relationship satisfaction and commitment on assumed similarity in HonestyHumility and Openness to Experience. Journal of Research in Personality, 104209. https://doi.org/10.1016/j.jrp.2022.104209 
DISTINCTIVE ASSUMED SIMILARITY IN HONESTY-HUMILITY AND OPENNESS

TO EXPERIENCE

Author Contributions

Jie Liu and Christina Lehane designed the study, prepared the online survey, and collected the data. Jie Liu prepared the manuscript, and Ville-Juhani Ilmarinen performed the analyses. All authors contributed in interpreting the results and editing the manuscript.

\section{Funding Statement}

The author(s) disclosed receipt of the following financial support for the research, authorship, and/or publication of this article: Parts of this research was funded by Youth Foundation to Jie Liu from Northeast Normal University (20XQ003). This research was supported by the Academy of Finland research grant 338891 to VilleJuhani Ilmarinen.

\section{Acknowledgment}

The authors thank Lara Schleifenbaum for her help in initial online survey preparation.

\section{Conflict of Interest}

The author(s) declare no potential conflicts of interest with respect to the research, authorship, and/or publication of this article. 
DISTINCTIVE ASSUMED SIMILARITY IN HONESTY-HUMILITY AND OPENNESS TO EXPERIENCE

Abstract

This study examined distinctive assumed similarity in Honesty-Humility and Openness to Experience and its influencing factors. With samples from the British Isles, China, and Denmark and with both individual and dyadic data $(N=1196)$, the meta-analytical results show that distinctive assumed similarity in Honesty-Humility and Openness to Experience was higher than in Emotionality, Extraversion, Agreeableness, and Conscientiousness in intimates after controlling for normativity. Also, relationship satisfaction and commitment moderated distinctive assumed similarity in Honesty-Humility and Openness to Experience, indicating that people high in relationship satisfaction and commitment perceived their partner to be more similar to them regarding those two traits relative to people low in relationships satisfaction and commitment. Implications and limitations of this research are also discussed.

Key words: assumed similarity, personality traits, relationship quality, couple perception 
DISTINCTIVE ASSUMED SIMILARITY IN HONESTY-HUMILITY AND OPENNESS TO EXPERIENCE

Seeing you in me: Moderating role of relationship satisfaction and commitment on assumed similarity in Honesty-Humility and Openness to Experience

Assumed similarity has been widely studied in the field of personality, and has been reported to be moderate-to-large among people with different levels of acquaintance, from strangers to couples (Cohen et al., 2013; Lee et al., 2009; Liu et al., 2018; Paunonen \& Hong, 2013; Thielmann et al., 2020; Watson et al., 2000) Moreover, many studies have found that assumed similarity is particularly pronounced for some personality traits, such as Honesty-Humility and Openness to Experience in the HEXACO model (Lee et al., 2009; Thielmann et al., 2020). This pattern also holds in intimate relationships (Liu et al., 2018). However, few studies have examined the moderators of assumed similarity in Honesty-Humility and Openness to Experience in intimate partners. This study not only aims to replicate previous findings that assumed similarity is higher in Honesty-Humility and Openness to Experience between intimate partners, but also to explore whether relationship satisfaction and commitment moderate assumed similarity in these two traits.

\section{Assumed similarity}

Using one's characteristics to infer characteristics of others is important. Because it greatly reduces one's cognitive load of making judgement of another person given that individuals need to form fast judgement about others' characteristics in various settings in everyday life. From an evolutionary perspective, being able to rapidly assess what others are like is essential because it facilitates predicting others' behaviors, and thus allows one to make quick reactions (Cosmides \& Tooby, 1992; Fiske, 1993).

Actually, this phenomenon has been examined with different theoretical approaches, and accordingly has received different names, such as attributive 
DISTINCTIVE ASSUMED SIMILARITY IN HONESTY-HUMILITY AND OPENNESS TO EXPERIENCE

projection (e.g., Sherwood, 1981), false consensus (e.g., Marks \& Miller, 1987), the self-based heuristic (e.g., Ready et al., 2000), and egocentrism (e.g., Murray et al., 2002). Attributive projection is most commonly used to describe defensive projection - attributing one's own unacceptable urges to others (Sherwood, 1981). False consensus is characterized by individuals' tendency to see their own choices and judgments shared by most people, and thus to meet their desire and justify their actions as common, appropriate, and correct (Marks \& Miller, 1987). The self-based heuristic describes the strategy that observers use when limited trait information about another person is provided, in which case they proceed to "fill in the gaps" with trait information that reflects their own personality (Ready et al., 2000). Egocentrism describes people's tendency to use themselves as a benchmark to make unjustified inferences about their intimate partner (Murray et al., 2002). Although all these terms describe the basic phenomenon of how people form impression of others, they have some restrictions, either under certain condition (e.g., when traits information is limited) or in specific setting (e.g., in romantic scenario). By contrast, assumed similarity does not imply any restrictions. It is defined as the correspondence between how a person sees others and how the person sees her/himself (Kenny, 1994), and is typically operationalized as correlations between one's self-report attributes and her/his observer ratings of another person's corresponding attributes (Lee et al., 2009; Thielmann et al., 2020). Additionally, assumed similarity is used more broadly when examining perceptions concerning personality traits between dyads with different levels of acquaintance, from stranger to intimate partner (Lee et al., 2009; Liu et al., 2018; Thielmann et al., 2020; Watson et al., 2000), and is favored by previous researchers who share our analytical approach (e.g., Locke et al., 2012). Accordingly, we choose to use the term assumed similarity in our manuscript. 
DISTINCTIVE ASSUMED SIMILARITY IN HONESTY-HUMILITY AND OPENNESS TO EXPERIENCE

More relevant to our research, assumed similarity has been found to be vital to intimate relationships. For example, assuming a person to be similar to oneself is predictive of one's initial attraction toward that person (Montoya et al., 2008). Also, by assuming their partners are mirrors of themselves in terms of personal attributes, values, and day-to-day feelings, people can experience enhanced intimacy and feelings of being understood (Aron et al., 1991; Murray et al., 2002). Additionally, assuming similarity with one's partner in interpreting thoughts, feelings, as well as important concepts related to good marriage (e.g., love, understanding, trust) is strongly related to better relation functioning (Arias \& O'Leary, 1985; Thomas et al., 1997).

\section{Assumed similarity in personality}

Given the importance of assumed similarity, no wonder it has been widely studied in various characteristics, such as attitudes and beliefs (Paunonen \& Kam, 2014), emotions (Beer et al., 2013), end-of-life decision making (McDade-Montez et al., 2013), and personality attributes (Lee et al., 2009). Indeed, research of assumed similarity in personality is particularly fruitful, typically organized either with the Five-Factor Model (FFM; Costa \& McCrea, 1992) or the HEXACO model (Ashton et al., 2004). Generally speaking, the HEXACO Extraversion, Conscientiousness and Openness to Experience virtually mirror their FFM counterparts, whereas the HEXACO Emotionality and Agreeableness represent alternative rotations of FFM Neuroticism and Agreeableness (Ashton \& Lee, 2007; Ashton et al., 2014). The most striking difference between the two personality models is the addition of HonestyHumility in the HEXACO model, which comprises characteristics such as being honest, loyal, and sincere versus being boastful, hypocritical, and pretentious (Lee \& Ashton, 2004, 2006). 
DISTINCTIVE ASSUMED SIMILARITY IN HONESTY-HUMILITY AND OPENNESS TO EXPERIENCE

With the FFM, Paunonen and Hong (2013) reported assumed similarity ranged from 0.23 to 0.44 for roommates across the FFM traits. Watson et al. (2000) reported an average assumed similarity of $r=.31$ for Openness to Experience, while the average assumed similarity for the other Big Five traits was comparatively weak (.13 $\leq r \leq .21)$ in a sample comprising different forms of dyads (e.g., friendship dyads, dating couples, married couples). With the HEXACO model, Lee et al. (2009) reported assumed similarity in Honesty-Humility $(r=.44$ and $r=.46)$ and Openness to Experience $(r=.35$ and $r=.30)$ was higher compared to that of the remaining four HEXACO traits $(-.07 \leq r \leq .12)$ in two Canadian samples of well-acquainted dyads (e.g., friends, relatives, and romantic partners). Cohen et al. (2013) found that assumed similarity in a sample of co-worker dyads ranged from 0.25 to 0.61 across the HEXACO personality traits. More recently, Thielmann et al. (2020) metaanalyzed previous studies examining assumed similarity with both the FFM and the HEXACO model, and they reported that assumed similarity ranged from 0.09 to 0.25 for the FFM traits, and -0.02 to 0.48 for the HEXACO traits. Thielmann et al. (2020) also examined assumed similarity in the HEXACO personality traits between strangers, and they found that strangers assumed strong similarity in HonestyHumility and Openness to Experience (albeit weaker) across different samples. Thus, previous research demonstrates that assumed similarity is ubiquitous in personality, and this is particularly true for certain personality traits, such as Honesty-Humility and Openness to Experience.

Concerning assumed similarity for personality in intimate relationships, the results actually are quite consistent, also especially regarding Honesty-Humility and Openness to Experience. For example, Liu et al. (2018) asked Danish participants currently involved in intimate relationships to report their own and their partner's 
DISTINCTIVE ASSUMED SIMILARITY IN HONESTY-HUMILITY AND OPENNESS TO EXPERIENCE

personality traits with the HEXACO model, and they found that individuals perceived their partners to be significantly more similar to them regarding Honesty-Humility and Openness to Experience (a bit weaker) compared to the other HEXACO traits. Indirectly supporting the finding of high assumed similarity in Honesty-Humility, McCrae et al., (2008) recruited couples from the Czech Republic, Russia, and the United States, and reported consistent assumed similarity between spouses for the FFM-Agreeableness facets Straightforwardness $(.29 \leq r \leq .38)$ and Modesty $(.19 \leq r$ $\leq .45$ ), which conceptually and empirically overlap with Honesty-Humility (Ashton et al., 2014; Ashton \& Lee, 2005). McCrae et al., (2008) also found that assumed similarity ranged from .21 to .22 between spouses in Openness. Additionally, Watson et al. (2000) reported that assumed similarity in Openness was consistently strong in dating and married couples compared to the other personality traits.

The complexity of assumed similarity between intimate partners is that partners might, indeed, have similar personality traits. This is highly likely because people have been found to prefer a similar partner personality-wise (Figueredo et al., 2006; Liu, Ludeke, Haubrich, et al., 2018), and because ideal preference is predictive of one's actual partner choice (Campbell et al., 2016; Gerlach et al., 2017). Indeed, actual similarity in personality has been reported to be positive in some studies, especially concerning Openness. For example, Watson et al. (2000) found that dating couples shared similarity in Extraversion $(r=0.20)$ and Openness $(r=0.36)$, but not in Neuroticism, Agreeableness and Conscientiousness $(.07 \leq r \leq .13)$. However, this pattern was not replicated in their sample comprising married couples where Watson et al. (2000) reported insignificant correlations for actual similarity across all FFM traits. McCrae et al. (2008) reported consistent and significant actual similarity in Openness $(.14 \leq r \leq .23)$ between spouses across the Czech Republic, Russia, and the 
DISTINCTIVE ASSUMED SIMILARITY IN HONESTY-HUMILITY AND OPENNESS TO EXPERIENCE

United States compared to the mixed results in other FFM traits $(-0.08 \leq r \leq 0.26)$.

Noticeably, actual similarity in Straightforwardness and Modesty, which is conceptually related to Honesty-Humility as mentioned earlier, ranged from 0.09 to 0.25 , with mixed significance from country to country. More recently, Leikas et al. (2018) found similarity for all FFM personality traits (except for Neuroticism) in Finnish couples, with similarity in Openness most pronounced $(r=.30)$.

To sum up, previous research has provided a quite mixed picture of actual similarity in personality characteristics between intimate dyads. This further complicates the study of assumed similarity in personality between intimate dyads as it is difficult to decide in advance when the potential confound of actual similarity will influence assumed similarity. Perhaps due to this reason, few study examining assumed similarity in personality in intimate partners have controlled the effects of actual similarity. Only recently, Liu et al. (2018) ruled out the potential impact of actual similarity on assumed similarity in personality perception between intimate dyads in their Study 2. They collected self-reported personality traits and observer reports of partner's personality traits from intimate dyads, examining assumed similarity in Honesty-Humility and Openness to Experience after controlling for actual similarity. They found that assumed similarity was highest in HonestyHumility, followed by Openness to Experience. Noticeably, their results show that actual similarity between intimate dyads was quite weak, ranging from -.15 to .07 , with -.04 for Honesty-Humility and .07 for Openness to Experience. Altogether, previous research has consistently reported higher assumed similarity in HonestyHumility and Openness to Experience in intimate dyads even after controlling for actual similarity.

The Moderating Role of Relationship Satisfaction and Commitment 
DISTINCTIVE ASSUMED SIMILARITY IN HONESTY-HUMILITY AND OPENNESS TO EXPERIENCE

Previous research has provided strong support for the phenomenon that people tend to see their partner as similar to them particularly concerning Honesty-Humility and Openness to Experience, which is also true even after controlling for actual similarity. However, no study so far has examined factors influencing assumed similarity in Honesty-Humility and Openness to Experience in intimate relationships. This study aims to examine whether relationship satisfaction and commitment are two potential moderators.

Relationship satisfaction describes how people feel toward their relationships (Rusbult et al., 1998). Being in a satisfying relationship motivates people to see their partner in a rosy light. For example, people in happy relationships are likely to overestimate the positive qualities of their partners, evaluating their partners as more intelligent, physically attractive, skilled, or trustworthy (Murray et al., 2000). Additionally, partners in satisfied relationships make more positive and generous attributions about their relationships and partners (Fincham \& Bradbury, 1993; Murray et al., 1996).

Commitment involves a long-term orientation to the relationship, feelings of attachment to a partner, and desire to maintain the relationship (Arriaga \& Agnew, 2001; Rusbult et al., 1998). Commitment tends to color the way people perceive their partner, allowing them to view their partner in a favorable way. People in committed relationships tend to deliberately devalue attractive relationship alternatives (Johnson \& Rusbult, 1989; Maner et al., 2009). They are also more likely to perceive their partner as more responsive when discussing personal problems, even after controlling for the partner's self-reported behavior and ratings of the partner's behavior by objective raters (Lemay \& Neal, 2014). Conversely, people who want to avoid 
DISTINCTIVE ASSUMED SIMILARITY IN HONESTY-HUMILITY AND OPENNESS TO EXPERIENCE

intimacy tend to perceive their partner's care as less voluntarily (Beck \& Clark, 2010).

Prior studies have suggested that relationship satisfaction and commitment tend to motivate people to generate positive evaluations toward their partners and these positive evaluation serves to fulfil people's certain desire, i.e., to maintain or to dissolve their relationships. Since people typically desire to have a partner sharing similarity in Honesty-Humility and Openness to Experience (Liu, Ludeke, Haubrich, et al., 2018), being in a happy and committed relationship should motivate people to view their partner in such a way. Thus, we hypothesize that relationship satisfaction and commitment moderates assumed similarity in Honesty-Humility and Openness to Experience between intimate partners.

\section{The Current Study}

This study aims to replicate the previous finding that people assume higher similarity in Honesty-Humility and Openness to Experience with their partners, and to extend previous findings by exploring potential moderators. Particularly, we are interested in whether people perceive their partner to share their distinct identity. To achieve this, we decomposed assumed similarity into a distinctive and a normative component. A normative component is an average score of a personality trait across all individuals, and a distinctive component is the degree to which an individual's personality score deviates from that average. It is highly likely that assumed similarity in personality between partners is due to the normative component since all individuals perceive others to be somewhat similar to the average person. Indeed, assumed similarity in personality between two random persons is never negligible, especially concerning Honesty-Humility and Openness to Experience (Thielmann et al., 2020). Accordingly, assumed similarity in these two traits between intimate 
DISTINCTIVE ASSUMED SIMILARITY IN HONESTY-HUMILITY AND OPENNESS TO EXPERIENCE

partners may be inflated by the normative component. As Rogers et al. (2018) pointed out that normative responses make it difficult to interpret meaningfully indexes of profile correspondence. Thus, it is important to dissect the distinctive component from the overall assumed similarity by controlling for the normative component to assess whether intimate partners see each other to be alike in their idiosyncratic way concerning Honesty-Humility and Openness to Experience.

Accordingly, we primarily focus on the distinctive component in assumed similarity (i.e., distinctive assumed similarity) by controlling for the normative component (i.e., normativity). We borrow the method from distinctive actual similarity (Furr, 2008; Liu \& Ilmarinen, 2020; Wood \& Furr, 2016). Specifically, we index assumed similarity with personality items, which can not only control for the normative component, but also capture more nuances (Seeboth \& Mõttus, 2018). Furthermore, examining distinctive profiles while indexing trait-specific sub-profiles in the analysis allows for direct comparisons and contrasts across the six traits in the HEXACO model of personality structure, instead of conducting separate analyses for each trait. This comparability also extends to contrasting moderated associations in these models.

To recap, we hypothesize that people present higher distinctive assumed similarity with their partners in Honesty-Humility and Openness to Experience (Hypothesis 1), and distinctive assumed similarity in these two traits is moderated by relationship satisfaction and commitment (Hypothesis 2). We examine these hypotheses with samples from the British Isles, China, and Denmark, with both individual data and dyadic data. A meta-analysis is conducted across all samples to 
DISTINCTIVE ASSUMED SIMILARITY IN HONESTY-HUMILITY AND OPENNESS TO EXPERIENCE

provide a clear outlook to these two hypotheses, especially given the very little variance in each individual sample ${ }^{1}$.

\section{Method $^{2}$}

\section{Participants and Procedures}

Danish sample. The Danish sample was reused from Study 1 in Liu et al. (2018) and only for the meta-analysis of distinctive assumed similarity in the HEXACO traits. Descriptive statistics of all samples are presented in Table 1.

British Isles sample. The British Isles sample included participants from Wales, England, Scotland, and Ireland (Northern and Republic), and they were recruited via Facebook advertising. 417 participants started our survey, 306 passed the two attention checking items. 296 participants without missing values were included.

Chinese sample 1. The first Chinese sample was recruited via online advertisements. 162 participants completed our surveys, 141 were included since they passed the attention checking items and did not respond repetitively to personality questionnaires (more than 10 consecutive items with the same response).

Chinese sample 2. The second Chinese sample was recruited via advertising this study to college students and was conducted online. 364 participants completed our survey, and 8 were excluded due to carelessness (i.e., indicating that their relationship length was 0) or repetitive responses.

Chinese sample 3. The third Chinese sample was a sample of couples and was merged from two couple samples. One (118 intimate dyads) is from Study 2 of Liu et al. (2018) where relationship satisfaction and commitment was collected but had not been used anywhere before. The other is from the second Chinese sample where 58

\footnotetext{
${ }^{1}$ Results for each individual sample can be found in online supplemental materials.

${ }^{2}$ Please note that this research was not pre-registered.
} 
DISTINCTIVE ASSUMED SIMILARITY IN HONESTY-HUMILITY AND OPENNESS TO EXPERIENCE

intimate dyads participated (which was excluded from the second Chinese sample).

There were 315 participants after removing participants with repetitive responses.

Please note that in all samples we have excluded participants with any missing data or repetitive responses. Removing participants with repetitive responses is because in profile analysis (See more information in Analytical approach), variability in the profile is obviously zero if all responses are the same (i.e., the 10-item survey for one personality trait from self-report and partner report), and when there is no variability, covariation (i.e., correlation) cannot be estimated. Similar approach for repetitive responses have been used by Mac Giolla and Kajonius (2019). Excluding participants with missing value is because the between-person variability in profile correlations (random slopes in the model) could be artificially inflated if the profiles do not consist of same items (e.g., having missing values) for all participants. In general, the number of excluded participants based on "any missing" was not that large in any of the samples (largest in Chinese sample 1, about 13\%). Given these reasons, we set up the exclusion criteria in our manuscript, but we did make the unprocessed raw data (without exclusion) available alongside the processed data (with exclusion) in OSF for interested readers.

\section{Statement about power}

The power to detect significant associations (type I-error set at .05) between relationship variables and distinctive similarity preference were tested for effect sizes of $r=.10, .20$, and .30 with the total sample size of 1108 . This examination was done with a simulation study that can be found at (https://osf.io/k9nsw/). In the simulation, a fixed effect of $q=.30$ for distinctive assumed similarity was used while the between-subject variation for this slope was sampled with a standard deviation of .15 (95\% of the population would have assumed distinctive similarity between $q=.00$ 
DISTINCTIVE ASSUMED SIMILARITY IN HONESTY-HUMILITY AND OPENNESS TO EXPERIENCE

and $q=.60$ ). The power to detect the moderation effect for relationship variables on distinctive assumed similarity was $.72,>0.99$, and $>0.99$ (all 1000 simulated replicated produced the result) for $r \mathrm{~s}$ of $.10, .20$, and .30 , respectively.

\section{Measures}

Personality. Participants' self-report personality was assessed via the 60 -item HEXACO Personality Inventory-Revised (HEXACO-60, Ashton \& Lee, 2009), measuring each personality trait with 10-item. Partner's personality was assessed via an adapted version of the self-report HEXACO-60 by replacing the first-person pronoun with "my partner" for each item in the original version and making grammatical changes only when necessary. For example, the original item from the self-report scale is "Having a lot of money is not essentially important to me" (Honesty-Humility) and was adapted into "Having a lot of money is not essentially important to my partner" in the partner version. Participants were instructed to rate to what extent each item describes themselves or their partner from 1 (strongly disagree) to 5 (strongly agree). Cronbach's alphas of the self- and partner report ranged from .60 to .85 across samples.

Relationship Satisfaction. Relationship satisfaction was measured with the 7item Relationship Assessment Scale (RAS, Hendrick, 1988) in the British Isles sample, Chinese sample 1, sample 2, and the 58 dyads in sample 3. Sample items are "How good is your relationship compared to the most?", "How well does your partner meet your needs?". These questions were answered with a 5-point response scale $(1=$ not at all; 5 = very much). Cronbach's alpha of RAS ranged from .70 to .90 across samples. For the 118 Chinese intimate dyads, relationship satisfaction was measured by satisfaction scale from Rusbult et al. (1998). Sample items are "My relationship is much better than others' relationships", "Our relationship makes me very happy". 
DISTINCTIVE ASSUMED SIMILARITY IN HONESTY-HUMILITY AND OPENNESS TO EXPERIENCE

Cronbach's alpha of this satisfaction scale was .89. Since the two satisfaction scales measured the same construct, they were used interchangeably in previous studies (e.g., Pfund et al., 2020). For the sake of simplicity, we standardized the satisfaction scores and treated them as one relationship satisfaction dimension in all analyses.

Commitment. Commitment was measured using a 5-item commitment scale from Rusbult et al. (1998). Sample items are "I am committed to maintaining my relationship with my partner", "I want our relationship to last forever". These questions were answered with either 9-point response scales ( 1 = extremely disagree; $9=$ extremely agree $)$ or 5 -point response scales $(1=$ extremely disagree; $5=$ extremely agree). The 9-point response scales were recoded to correspond to the 5point response scales (i.e., $9=5,8=4.5 \ldots 1=1$; Liu et al., 2017), and composited scores were standardized as well. Cronbach's alpha of the commitment scale ranged from .80 to .89 across samples. An overview of all assessments, the raw datasets, and the analysis scripts can be found at (https://osf.io/k9nsw/).

\section{Analytical Approach}

To examine distinctive assumed similarity in the HEXACO traits and the moderation effects of relationship satisfaction and commitment, we used the multilevel approach (Biesanz, 2010; Rogers et al., 2018). By applying this approach separately to each sample, we centered all the personality item responses around the grand mean. From these, the normative profiles were calculated as means of each selfreport item. the distinctive profile for each participant was computed by centering each self-report item around its sample mean. Finally, self-ratings were scaled with within-subject standard deviation that was pooled across all participants. Partnerratings were scaled with similar method whereas normative profile was scaled with the standard deviation of the normative profile in each sample. Standardization 
DISTINCTIVE ASSUMED SIMILARITY IN HONESTY-HUMILITY AND OPENNESS TO EXPERIENCE

allowed for direct interpretation and comparisons of the main effects of distinctive assumed similarity.

To investigate distinctive assumed similarity in personality ratings, a multilevel profile analysis model was constructed where partner-report profiles were regressed on distinctive self-report profiles, normative profiles, and their random effects across subjects. By adding normative profiles as one predictor in the multilevel model, we can not only practically control for it, but can also statistically demonstrate its impact ${ }^{3}$. For dyadic Chinese sample 3, additional random effect was included at the level of dyad which accounted for dyadic similarity in partner-reports. Moderated associations were examined from cross-level interactions between distinctive selfreport profiles and the relationship variables, while also including similar effects for normativity. Trait-specific associations were estimated by introducing trait domain as a fixed effect to the model and examining the marginal effects for each trait and the contrasts between traits to understand their differences. All analyses were run in R with the lme4-package (Bates et al., 2015). Marginal effects were examined with the emmeans-package (Lenth, 2019). Satterthwhaite's approximation for degrees of freedom was used in testing the significance of single fixed parameter estimates, and more general model improvements were examined with likelihood-ratio tests.

After fitting the described multilevel profile analysis models for each sample separately, these effects were pooled across samples in a random effect meta-analysis using the metafor-package (Viechtbauer, 2010). Sample-specific results were interpreted only when there was heterogeneity in the estimates across the samples. In

\footnotetext{
${ }^{3}$ Since we primarily focused on distinctive assumed similarity in our manuscript, we didn't detail the results of the normative component of self-ratings on partner ratings. But the analytical scripts were presented in online supplementary materials for interested readers.
} 
DISTINCTIVE ASSUMED SIMILARITY IN HONESTY-HUMILITY AND OPENNESS TO EXPERIENCE

all pairwise comparisons, $p$-values were adjusted with the Holm-method to keep the family-wise error rates at .05 (Holm, 1979).

\section{Results}

Meta-analysis was used to incorporate all the samples and to provide a clear picture of the results. The meta-analytical results of distinctive assumed similarity for the HEXACO traits are presented in Figure 1. Distinctive assumed similarity for Honesty-Humility (.30) and Openness to Experience (.20) was descriptively higher than the other four traits $(.01 \leq q \leq .08)$.

To examine Hypothesis 1 that distinctive assumed similarity in HonestyHumility and Openness to Experience is significantly higher than Emotionality, Extraversion, Agreeableness, and Conscientiousness, contrasts between estimates of distinctive assumed similarity between Honesty-Humility as well as Openness to Experience and the other four HEXACO trait was performed. The results revealed that distinctive assumed similarity in Honesty-Humility was higher than Emotionality $(b=0.29, p<.001,95 \%$ CI $[0.25,0.33])$, Extraversion $(b=0.22, p<.001,95 \% \mathrm{CI}$ $[0.18,0.26])$, Agreeableness $(b=0.22, p<.001,95 \%$ CI $[0.18,0.26])$, and Conscientiousness $(b=0.28, p<.001,95 \%$ CI $[0.24,0.32])$. Distinctive assumed similarity in Openness to Experience was higher than Emotionality $(b=0.19, p$ $<.001,95 \%$ CI $[0.15,0.23])$, Extraversion $(b=0.12, p<.001,95 \%$ CI $[0.08,0.16])$, Agreeableness $(b=0.12, p<.001,95 \%$ CI $[0.08,0.16])$, and Conscientiousness $(b=$ $0.18, p<.001,95 \%$ CI $[0.14,0.22])$. Distinctive assumed similarity was also higher for Honesty-Humility than for Openness to Experience ( $b=0.10, p<.001,95 \%$ CI $[0.06,0.14])$. The random effects models showed that heterogeneity across samples in distinctive assumed similarity in Honesty-Humility and Openness to Experience was 
DISTINCTIVE ASSUMED SIMILARITY IN HONESTY-HUMILITY AND OPENNESS TO EXPERIENCE

non-significant, indicating that these results are invariant across countries. Thus, Hypothesis 1 is fully supported.

Next, we examined Hypothesis 2 that distinctive assumed similarity in Honesty-Humility and Openness to Experience is moderated by Relationship satisfaction and commitment. The results showed that relationship satisfaction and commitment (See Figure 2) significantly moderated distinctive assumed similarity in Honesty-Humility and Openness to Experience. Point estimates of distinctive assumed similarity for these two traits at low (Mean - 1SD), average (Mean), and high $($ Mean $+1 \mathrm{SD})$ levels of relationship satisfaction and commitment are presented in Table 2. The general pattern shows that people high in relationship satisfaction and commitment tend to see their partner as more similar to them regarding these two traits compared to those low in relationship satisfaction and commitment. Moderated associations for Honesty-Humility and Openness to Experience by commitment, and for Openness to Experience by satisfaction showed heterogeneity across the studies (see Figure 2), but these heterogeneities were not accounted for by country, $\chi^{2}(1)$ $=1.25, p=.264, \chi^{2}(1)=0.03, p=.862$, and $\chi^{2}(1)=0.10, p=.758$, respectively. Thus, Hypothesis 2 is also supported.

\section{Discussion}

With samples from the British Isles, China, and Denmark and with both individual data and dyadic data, we found that distinctive assumed similarity in Honesty-Humility and Openness to Experience was consistently higher than Emotionality, Extraversion, Agreeableness, and Conscientiousness in intimate partners after controlling for normativity, supporting Hypothesis 1. Also, relationship satisfaction and commitment moderated distinctive assumed similarity in HonestyHumility and Openness to Experience, which indicates that people with higher levels 
DISTINCTIVE ASSUMED SIMILARITY IN HONESTY-HUMILITY AND OPENNESS TO EXPERIENCE

of relationship satisfaction and commitment perceived their partner to be more similar to them regarding those two personality traits compared to people with lower levels of relationships satisfaction and commitment, supporting Hypothesis 2. These results are consistent across different cultures, providing rather strong support for our hypotheses.

Higher assumed similarity between intimate partners in Honesty-Humility and Openness to Experience was found across all countries. This not only perfectly mirrors the conclusions from Liu et al. (2018), but also extends their conclusions with larger samples, stricter analytical strategies, and more diverse cultures. Also, by focusing on distinctive assumed similarity, we found that people, indeed, perceive their partner to share their distinctive identity in terms of Honesty-Humility and Openness to Experience. Our results also echo the conclusion from Lee et al. (2009) that people tend to overestimate similarity in Honesty-Humility and Openness to Experience to persons with whom they share a close relationship by showing that assumed similarity in these two traits is higher in intimate relationships - a relation that might be considered as the closest form of relation (Bradbury \& Karney, 2010).

One reason to explain the pronounced assumed similarity in Honesty-Humility and Openness to Experience is their strong relation with personal values relative to the other HEXACO traits (Lee et al., 2009; Liu, Ludeke, Haubrich, et al., 2018; Thielmann et al., 2020). In Schwartz's values framework (Schwartz, 1992; Schwartz et al., 2012), there are two basic dimensions of personal values, Self-Transcendence versus Self-Enhancement and Openness to Change versus Conservation. The former contrasts preferences for equality, honesty, loyalty, and social justice to preferences for authority, competence, social power, and wealth, and the latter contrasts preferences for creativity, curiosity, freedom, and novelty to preferences for 
DISTINCTIVE ASSUMED SIMILARITY IN HONESTY-HUMILITY AND OPENNESS TO EXPERIENCE

obedience, security, social order, and tradition. Honesty-Humility, characterized by sincerity, fairness, greed-avoidance, and modesty, is well-aligned with SelfTranscendence (vs. Self-Enhancement). Openness to Experience, characterized by aesthetic appreciation, inquisitiveness, creativity, and unconventionality, is wellaligned with Openness to Change (vs. Conservation). Thielmann et al. (2020) has suggested that indiviudals generally expect others to be similar to themselves on traits that are strongly value-related, regardless of their levels of acquaintance with others.

Besides the broad explanation, the specific setting of intimate relationships also entails another interpretation-viewing one's partner to be particularly and distinctively similar in Honesty-Humility and Openness to Experience may be because assumed similarity in these two traits is important to intimate relationship. On the one hand, assuming similarity in Honesty-Humility and Openness to Experience with one's partner can help to solve the discrepancy between one's ideal partner preference and actual partner choice concerning these two traits. Though individuals prefer their ideal partner to be highly similar in Honesty-Humility and Openness to Experience when single, it is not often the case that they can achieve this in reality (Liu, Ludeke, Haubrich, et al., 2018; Liu et al., 2018). Indeed, the distinctive actual similarity ${ }^{4}$ in Honesty-Humility $(r=0.04, p=0.004)$ and Openness to Experience $(r=$ 0.02, $p=0.114$ ) between Chinese couples was relatively weak in our study. However, discrepancies between one's ideal partner and real-life partner have a negative impact on one's relationships (Campbell et al., 2001). Perceiving one's partner to be similar to oneself on these two traits could be an effective strategy to buffer the potential negative impact. On the other hand, assuming similarity in these two traits with one's

\footnotetext{
${ }^{4}$ More information about distinctive actual similarity in Chinese sample 3 can be found in Table S4 in online supplementary materials.
} 
DISTINCTIVE ASSUMED SIMILARITY IN HONESTY-HUMILITY AND OPENNESS TO EXPERIENCE

partner may facilitate relationship functioning in everyday life. Take Honesty-

Humility as an example, if a person is particularly manipulative, she/he might see the partner as more manipulative than others. By contrast, if a person is especially kind and selfless, she/he is likely to perceive the partner in a similar manner. The manipulative person is likely to initiate immoral or even illegal behaviors (e.g., tax evasion, corruption) with the expectation that her/his partner would be an accomplice, whereas the kind person is likely to engage in pro-social actions (e.g., donating to charity, helping others) with the assumption that her/his partner would pursue the same. Future studies could examine whether distinctive assumed similarity in Honesty-Humility and Openness to Experience in couples is related to relationship functioning.

Extending previous research on assumed similarity in Honesty-Humility and Openness to Experience, our study found that distinctive assumed similarity on these two traits was influenced by relationship satisfaction and commitment. Specifically, we found that people in happier and more committed relationships were more likely to view their partner as similar to them in Honesty-Humility and Openness to Experience compared to those who are in unhappier and less committed relationships. There are some potential reasons to explain this effect. Perhaps people in satisfied and committed relationships are more likely to be kind, trustworthy, loyal, and open to their partner, which could elicit similar reactions from their partner, causing them to reach a conclusion of similarity. Perhaps people in satisfied and committed relationships might just ignore their partner's behaviors and emotions suggesting dissimilarity in Honesty-Humility and Openness to Experience, and selectively attend to their partner's actions implying similarity. Or perhaps people in satisfied and committed relationships might attribute their partner's daily actions that indicate 
DISTINCTIVE ASSUMED SIMILARITY IN HONESTY-HUMILITY AND OPENNESS TO EXPERIENCE

dissimilarity in the target personality traits to environmental factors, whereas

behaviors implying similarity may be attributed to their personality. So far, we have focused on discussing the impact of relationship satisfaction and commitment on assumed similarity in Honesty-Humility and Openness to Experience. But given the correlational nature of our data, we cannot test the casual implication of these variables. Logically speaking, perceiving partner to be uniquely similar in HonestyHumility and Openness to Experience may also help to promote relationship satisfaction and commitment. For example, Murray et al. (2002) reported that people in satisfying and stable relationships tend to perceive their partner to be similar with themselves in interpersonal traits like warmth, kindness, and openness which reflect some aspects of Honesty-Humility and Openness to Experience. Future research could continue to examine these possibilities.

Besides the theoretical implication, our research also has some implications for methods regarding assumed similarity. With the flexible multilevel profile analysis approach, we were able to statistically contrast between assumed similarity in HEXACO trait sub-profiles and to separately examine the moderated associations for each trait within the same model while also making sure that normative responses would not blur the interpretations of these associations. Furthermore, with the HEXACO personality items indexing distinctive assumed similarity, we are able to discern how much variance in distinctive assumed similarity is accounted for by trait domains and personality items respectively. We found that approximately two thirds of the heterogeneity in distinctive assumed similarity takes place between traits and approximately one third remains between the items within the same scale ${ }^{5}$ This aligns quite well with recent research suggesting that models with personality questionnaire

\footnotetext{
${ }^{5}$ Detailed results can be found in the online supplementary materials.
} 
DISTINCTIVE ASSUMED SIMILARITY IN HONESTY-HUMILITY AND OPENNESS TO EXPERIENCE

items as predictors tend to outperform models with personality domains as predictors (Seeboth \& Mõttus, 2018). Together, these results indicate that personality items can capture more nuances relative to trait domains in terms of representing personality.

There are some limitations in this study. Firstly, most participants across these samples were female, which may prevent us from generalizing our conclusion to more gender-balanced samples. Future research should strive for a gender-balanced sample to further examine this topic. Secondly, our participants are relatively young, which limits its representation of older samples. Future research could explore whether older couples still exhibit the same patterns. Third, though we have considered the actual similarity in personality when examining assumed similarity between intimate partners, it is only within the Chinese sample. Thus, it remains largely unknown about the impact of actual similarity on distinctive assumed similarity in partners from Denmark and British Isles that represent western cultures. Future research could aim to collect dyadic data of personality ratings from partners in western countries to tackle this issue. Also, we focused mainly on higher assumed similarity in HonestyHumility and Openness to Experience as well as its moderating factors, but we did not investigate the underlying mechanisms. Future research could aim to explore explanatory factors for these effects. Besides, our correlational data did not allow us to make causal inference of the relation between assumed similarity in HonestyHumility and Openness to Experience and relationship satisfaction and commitment. Perhaps assumed similarity in these two traits leads to good relationships, perhaps good relationships result from partners perceiving similarity with each other in these two traits, or perhaps assumed similarity in these two traits and good relationships perpetuate each other in a reciprocal way. Finally, the one-shot cross-sectional design did not allow us to examine the dynamic and the long-term effects of distinctive 
DISTINCTIVE ASSUMED SIMILARITY IN HONESTY-HUMILITY AND OPENNESS TO EXPERIENCE

assumed similarity in intimate relationships. Future research could use a daily diary design or longitudinal design to examine how distinctive assumed similarity in Honesty-Humility and Openness to Experience changes over time and how initial distinctive assumed similarity in these two traits affects the development and trajectory of intimate relationships.

\section{Conclusion}

With samples from the British Isles, China, and Denmark and with both individual data and dyadic data, our study found that distinctive assumed similarity in Honesty-Humility and Openness to Experience was consistently higher than Emotionality, Extraversion, Agreeableness, and Conscientiousness in intimate partners after controlling for normativity. We also found that relationship satisfaction and commitment moderated distinctive assumed similarity in Honesty-Humility and Openness to Experience, indicating that people with higher levels of relationship satisfaction and commitment perceived their partner to be more similar to them regarding those two personality traits compared to people with lower levels of relationships satisfaction and commitment. Our study not only replicates previous findings that assumed similarity in Honesty-Humility and Openness to Experience was higher than the other HEXACO traits with larger samples, stricter analytical strategies, and more diverse cultures, but also extends previous findings by exploring potential moderators of this phenomenon. 
DISTINCTIVE ASSUMED SIMILARITY IN HONESTY-HUMILITY AND OPENNESS

TO EXPERIENCE

\section{References}

Arias, I., \& O’Leary, K. D. (1985). Semantic and perceptual discrepancies in discordant and nondiscordant marriages. Cognitive Therapy and Research, 9(1), 51-60. https://doi.org/10.1007/BF01178750

Aron, A., Aron, E. N., Tudor, M., \& Nelson, G. (1991). Close relationships as including other in the self. Journal of Personality and Social Psychology, $60(2), 241-253$.

Arriaga, X. B., \& Agnew, C. R. (2001). Being committed: Affective, cognitive, and conative components of relationship commitment. Personality and Social Psychology Bulletin, 27(9), 1190-1203.

Ashton, M. C., \& Lee, K. (2005). Honesty-Humility, the Big Five, and the FiveFactor Model. Journal of Personality, 73(5), 1321-1354. https://doi.org/10.1111/j.1467-6494.2005.00351.x

Ashton, M. C., \& Lee, K. (2007). Empirical, theoretical, and practical advantages of the HEXACO model of personality structure. Personality and Social Psychology Review, 11(2), 150-166. https://doi.org/10.1177/1088868306294907

Ashton, M. C., Lee, K., \& de Vries, R. E. (2014). The HEXACO honesty-humility, agreeableness, and emotionality factors: A review of research and theory. Personality and Social Psychology Review, 18(2), 139-152. https://doi.org/10.1177/1088868314523838

Ashton, M. C., Lee, K., Perugini, M., Szarota, P., de Vries, R. E., Di Blas, L., Boies, K., \& De Raad, B. (2004). A six-factor structure of personality-descriptive adjectives: Solutions from psycholexical studies in seven languages. Journal 
DISTINCTIVE ASSUMED SIMILARITY IN HONESTY-HUMILITY AND OPENNESS

TO EXPERIENCE

of Personality and Social Psychology, 86(2), 356-366.

https://doi.org/10.1037/0022-3514.86.2.356

Ashton, M., \& Lee, K. (2009). The HEXACO-60: A short measure of the major dimensions of personality. Journal of Personality Assessment, 91(4), 340-345. https://doi.org/10.1080/00223890902935878

Bates, D., Mächler, M., Bolker, B., \& Walker, S. (2015). Fitting linear mixed-effects models using lme4. Journal of Statistical Software, 67(1), 1-48. https://doi.org/10.18637/jss.v067.i01

Beck, L. A., \& Clark, M. S. (2010). Looking a gift horse in the mouth as a defense against increasing intimacy. Journal of Experimental Social Psychology, 46(4), 676-679. https://doi.org/10.1016/j.jesp.2010.02.006

Beer, A., Watson, D., \& McDade-Montez, E. (2013). Self-other agreement and assumed similarity in neuroticism, extraversion, and trait affect:

Distinguishing the Effects of Form and Content. Assessment, 20(6), 723-737. https://doi.org/10.1177/1073191113500521

Biesanz, J. C. (2010). The social accuracy model of interpersonal perception: Assessing individual differences in perceptive and expressive accuracy. Multivariate Behavioral Research, 45(5), 853-885. https://doi.org/10.1080/00273171.2010.519262

Bradbury, T. N., \& Karney, B. R. (2010). Intimate relationships. New York, NY: W. W. Norton

Campbell, L., Chin, K., \& Stanton, S. C. E. (2016). Initial evidence that individuals form new relationships with partners that more closely match their ideal preferences. Collabra, 2(1), 2. https://doi.org/10.1525/collabra.24 
DISTINCTIVE ASSUMED SIMILARITY IN HONESTY-HUMILITY AND OPENNESS

TO EXPERIENCE

Campbell, L., Simpson, J. A., Kashy, D. A., \& Fletcher, G. J. O. (2001). Ideal standards, the self, and flexibility of ideals in close relationships. Personality and Social Psychology Bulletin, 27(4), 447-462. https://doi.org/10.1177/0146167201274006

Cohen, T. R., Panter, A. T., Turan, N., Morse, L., \& Kim, Y. (2013). Agreement and similarity in self-other perceptions of moral character. Journal of Research in Personality, 47(6), 816-830. https://doi.org/10.1016/j.jrp.2013.08.009

Cosmides, L., \& Tooby, J. (1992). Cognitive adaptations for social exchange. In J. H. Barkow, L. Cosmides, \& J. Tooby (Eds.), The adapted mind: Evolutionary psychology and the generation of culture. (pp. 163-228). New York, NY, US: Oxford University Press.

Costa, P. T., Jr., \& McCrae, R. R. (1992). NEO PI-R Professional Manual. Odessa, FL: Psychological Assessment Resources.

Figueredo, A. J., Sefcek, J. A., \& Jones, D. N. (2006). The ideal romantic partner personality. Personality and Individual Differences, 41(3), 431-441. https://doi.org/10.1016/j.paid.2006.02.004

Fincham, F. D., \& Bradbury, T. N. (1993). Marital satisfaction, depression, and attributions: A longitudinal analysis. Journal of Personality and Social Psychology. 64, 442-452.

Fiske, S. T. (1993). Social cognition and social perception. Annual Review of Psychology, 44(1), 155-194. https://doi.org/10.1146/annurev.ps.44.020193.001103

Furr, R. M. (2008). A framework for profile similarity: Integrating similarity, normativeness, and distinctiveness. Journal of Personality, 76(5), 1267-1316. https://doi.org/10.1111/j.1467-6494.2008.00521.x 
DISTINCTIVE ASSUMED SIMILARITY IN HONESTY-HUMILITY AND OPENNESS TO EXPERIENCE

Gerlach, T. M., Arslan, R. C., Schultze, T., Reinhard, S. K., \& Penke, L. (2017). Predictive validity and adjustment of ideal partner preferences across the transition into romantic relationships. Journal of Personality and Social Psychology. https://doi.org/10.1037/pspp0000170

Hendrick, S. S. (1988). A generic measure of relationship satisfaction. Journal of Marriage and the Family, 50(1), 93. https://doi.org/10.2307/352430

Holm, S. (1979). A simple sequentially rejective multiple test procedure. Scandinavian Journal of Statistics, 6(2), 65-79.

Johnson, D. J., \& Rusbult, C. E. (1989). Resisting temptation: Devaluation of alternative partners as a means of maintaining commitment in close relationships. Journal of Personality and Social Psychology, 57(6), 967.

Kenny, D. A. (1994). Interpersonal perception: A social relations analysis. New York, NY: Guilford Press.

Lee, K., \& Ashton, M. C. (2004). Psychometric properties of the HEXACO personality inventory. Multivariate Behavioral Research, 39(2), 329-358. https://doi.org/10.1207/s15327906mbr3902_8

Lee, K., \& Ashton, M. C. (2006). Further assessment of the HEXACO personality inventory: Two new facet scales and an observer report form. Psychological Assessment, 18(2), 182-191. https://doi.org/10.1037/1040-3590.18.2.182

Lee, K., Ashton, M. C., Pozzebon, J. A., Visser, B. A., Bourdage, J. S., \& Ogunfowora, B. (2009). Similarity and assumed similarity in personality reports of well-acquainted persons. Journal of Personality and Social Psychology, 96(2), 460-472. https://doi.org/10.1037/a0014059

Leikas, S., Ilmarinen, V.-J., Verkasalo, M., Vartiainen, H.-L., \& Lönnqvist, J.-E. (2018). Relationship satisfaction and similarity of personality traits, personal 
DISTINCTIVE ASSUMED SIMILARITY IN HONESTY-HUMILITY AND OPENNESS TO EXPERIENCE

values, and attitudes. Personality and Individual Differences, 123, 191-198. https://doi.org/10.1016/j.paid.2017.11.024

Lemay, E. P., \& Neal, A. M. (2014). Accurate and biased perceptions of responsive support predict well-being. Motivation and Emotion, 38(2), 270-286. https://doi.org/10.1007/s11031-013-9381-2

Lenth, R. (2019). emmeans: Estimated marginal means, aka least-squares means. https://CRAN.R-project.org/package=emmeans

Liu, J., \& Ilmarinen, V.-J. (2020). Core self-evaluation moderates distinctive similarity preference in ideal partner's personality. Journal of Research in Personality, 84, 103899. https://doi.org/10.1016/j.jrp.2019.103899

Liu, J., Ludeke, S. G., \& Zettler, I. (2017). The HEXACO correlates of authoritarianism's facets in the U.S. and Denmark. Personality and Individual Differences, 116, 348-352. https://doi.org/10.1016/j.paid.2017.05.015

Liu, J., Ludeke, S., Haubrich, J., Gondan-Rochon, M., \& Zettler, I. (2018). Similar to and/or Better than Oneself? Singles' ideal partner personality descriptions. European Journal of Personality, 32(4), 443-458. https://doi.org/10.1002/per.2159

Liu, J., Ludeke, S., \& Zettler, I. (2018). Assumed similarity in personality within intimate relationships. Personal Relationships, 25(3), 316-329. https://doi.org/10.1111/pere.12246

Locke, K. D., Craig, T., Baik, K.-D., \& Gohil, K. (2012). Binds and bounds of communion: Effects of interpersonal values on assumed similarity of self and others. Journal of Personality and Social Psychology, 103(5), 879-897. https://doi.org/10.1037/a0029422 
DISTINCTIVE ASSUMED SIMILARITY IN HONESTY-HUMILITY AND OPENNESS TO EXPERIENCE

Mac Giolla, E., \& Kajonius, P. J. (2019). Sex differences in personality are larger in gender equal countries: Replicating and extending a surprising finding. International Journal of Psychology, 54(6), 705-711. https://doi.org/10.1002/ijop.12529

Maner, J. K., Gailliot, M. T., \& Miller, S. L. (2009). The implicit cognition of relationship maintenance: Inattention to attractive alternatives. Journal of Experimental Social Psychology, 45(1), 174-179. https://doi.org/10.1016/j.jesp.2008.08.002

Marks, G., \& Miller, N. (1987). Ten years of research on the false-consensus effect: An empirical and theoretical review. Psychological Bulletin, 102(1), 72-90.

McCrae, R. R., Martin, T. A., Hrebícková, M., Urbánek, T., Boomsma, D. I., Willemsen, G., \& Costa, P. T. (2008). Personality trait similarity between spouses in four cultures. Journal of Personality, 76(5), 1137-1164. https://doi.org/10.1111/j.1467-6494.2008.00517.x

McDade-Montez, E., Watson, D., \& Beer, A. (2013). Similarity, agreement, and assumed similarity in proxy end-of-life decision making. Families, Systems, \& Health, 31(4), 366-381. https://doi.org/10.1037/a0033372

Montoya, R. M., Horton, R. S., \& Kirchner, J. (2008). Is actual similarity necessary for attraction? A meta-analysis of actual and perceived similarity. Journal of Social and Personal Relationships, 25(6), 889-922. https://doi.org/10.1177/0265407508096700

Murray, S., Holmes, J. G., Griffin, D. W., Murray, R. L., Holmes, J. G., \& Griffin, D. W. (1996). The benefits of positive illusions idealization and the construction of satisfaction in close relationships. Journal of Personality and Social Psychology. 70(1), 79-98. 
DISTINCTIVE ASSUMED SIMILARITY IN HONESTY-HUMILITY AND OPENNESS TO EXPERIENCE

Murray, S. L., Holmes, J. G., Bellavia, G., Griffin, D. W., \& Dolderman, D. (2002). Kindred spirits? The benefits of egocentrism in close relationships. Journal of Personality and Social Psychology, 82(4), 563-581. https://doi.org/10.1037/0022-3514.82.4.563

Murray, S. L., Holmes, J. G., Dolderman, D., \& Griffin, D. W. (2000). What the Motivated mind sees: Comparing friends' perspectives to married partners' views of each other. Journal of Experimental Social Psychology, 36(6), 600620. https://doi.org/10.1006/jesp.1999.1417

Paunonen, S. V., \& Hong, R. Y. (2013). The many faces of assumed similarity in perceptions of personality. Journal of Research in Personality, 47(6), 800815. https://doi.org/10.1016/j.jrp.2013.08.007

Paunonen, S. V., \& Kam, C. (2014). The accuracy of roommate ratings of behaviors versus beliefs. Journal of Research in Personality, 52, 55-67. https://doi.org/10.1016/j.jrp.2014.07.006

Pfund, G. N., Brazeau, H., Allemand, M., \& Hill, P. L. (2020). Associations between sense of purpose and romantic relationship quality in adulthood. Journal of Social and Personal Relationships, 37(5), 1563-1580. https://doi.org/10.1177/0265407520903807

Ready, R. E., Clark, L. A., Watson, D., \& Westerhouse, K. (2000). Self- and peerreported personality: Agreement, trait ratability, and the "self-based heuristic." Journal of Research in Personality, 34(2), 208-224. https://doi.org/10.1006/jrpe.1999.2280

Rogers, K. H., Wood, D., \& Furr, R. M. (2018). Assessment of similarity and selfother agreement in dyadic relationships: A guide to best practices. Journal of 
DISTINCTIVE ASSUMED SIMILARITY IN HONESTY-HUMILITY AND OPENNESS

TO EXPERIENCE

Social and Personal Relationships, 35(1), 112-134.

https://doi.org/10.1177/0265407517712615

Rusbult, C. E., Martz, J. M., \& Agnew, C. R. (1998). The investment model scale: measuring commitment level, satisfaction level, quality of alternatives, and investment size. Personal Relationships, 5(4), 357-387.

https://doi.org/10.1111/j.1475-6811.1998.tb00177.x

Schwartz. S. H. (1992). Universals in the content and structure of values: Theoretical advances and empirical tests in 20 countries. Advances in Experimental Social Psychology, 25, 1-65.

Schwartz, S. H., Cieciuch, J., Vecchione, M., Davidov, E., Fischer, R., Beierlein, C., Ramos, A., Verkasalo, M., Lönnqvist, J.-E., Demirutku, K., Dirilen-Gumus, O., \& Konty, M. (2012). Refining the theory of basic individual values. Journal of Personality and Social Psychology, 103(4), 663-688. https://doi.org/10.1037/a0029393

Seeboth, A., \& Mõttus, R. (2018). Successful explanations start with accurate descriptions: Questionnaire items as personality markers for more accurate predictions. European Journal of Personality, 32(3), 186-201. https://doi.org/10.1002/per.2147

Sherwood, G. G. (1981). Self-serving biases in person perception: A reexamination of projection as a mechanism of defense. Psychological Bulletin, 90(3), 445-459.

Thielmann, I., Hilbig, B. E., \& Zettler, I. (2020). Seeing me, seeing you: Testing competing accounts of assumed similarity in personality judgments. Journal of Personality and Social Psychology, 118(1), 172-198.

https://doi.org/10.1037/pspp0000222 
DISTINCTIVE ASSUMED SIMILARITY IN HONESTY-HUMILITY AND OPENNESS

TO EXPERIENCE

Thomas, G., Fletcher, G. J. O., \& Lange, C. (1997). On-line empathic accuracy in marital interaction. Journal of Personality and Social Psychology. 72(4), 839850.

Viechtbauer, W. (2010). Conducting meta-analyses in R with the metafor package. Journal of Statistical Software, 36(3), 1-48. https://doi.org/10.18637/jss.v036.i03

Watson, D., Hubbard, B., \& Wiese, D. (2000). Self-other agreement in personality and affectivity: The role of acquaintanceship, trait visibility, and assumed similarity. Journal of Personality and Social Psychology, 78(3), 546-558. https://doi.org/10.1037/0022-3514.78.3.546

Wood, D., \& Furr, R. M. (2016). The correlates of similarity estimates are often misleadingly positive: The nature and scope of the problem, and some solutions. Personality and Social Psychology Review, 20(2), 79-99. https://doi.org/10.1177/1088868315581119 
DISTINCTIVE ASSUMED SIMILARITY IN HONESTY-HUMILITY AND OPENNESS

TO EXPERIENCE

Table 1. Description of the Samples.

\begin{tabular}{cccccccccc}
\hline & & \multicolumn{4}{c}{ Age } & \multicolumn{4}{c}{ Relationship length (months) } \\
\hline & $n$ (women \%) & $M$ & $S D$ & $\min$ & $\max$ & $M$ & $S D$ & $\min$ & $\max$ \\
\cline { 2 - 10 } Danish sample & $92(84.8 \%)$ & 32.7 & 10.3 & 22 & 77 & 39.4 & 39.2 & 1 & 296 \\
British Isles & $292(90.1 \%)$ & 26.6 & 10.1 & 18 & 65 & 54.3 & 80.5 & 1 & 547 \\
sample & & & & & & & & \\
Chinese sample 1 & $141(82.3 \%)$ & 23.2 & 3.3 & 18 & 40 & 34.6 & 56.9 & 1 & 420 \\
Chinese sample 2 & $356(72.2 \%)$ & 23.3 & 4.4 & 18 & 45 & 29.8 & 34.1 & 1 & 228 \\
Chinese sample 3 & $315(50.5 \%)$ & 22.1 & 2.7 & 18 & 30 & 21.7 & 18.5 & 1 & 87 \\
Total & $1196(73.0 \%)$ & 24.5 & 7.1 & 18 & 77 & 34.9 & 51.6 & 1 & 547 \\
\hline
\end{tabular}


DISTINCTIVE ASSUMED SIMILARITY IN HONESTY-HUMILITY AND OPENNESS TO EXPERIENCE

Table 2. Simple Slopes for Distinctive Assumed Similarity in HEXACO Trait

Sub-Profiles by Relationship Satisfaction and Commitment.

\begin{tabular}{|c|c|c|c|c|c|c|}
\hline \multirow{3}{*}{$\begin{array}{l} \\
\text { Honesty-Humility } \\
\text { by satisfaction }\end{array}$} & \multicolumn{6}{|c|}{ Score on relationship variable } \\
\hline & \multicolumn{2}{|c|}{ Mean-1 SD } & \multicolumn{2}{|r|}{ Mean } & \multicolumn{2}{|c|}{ Mean+1SD } \\
\hline & & & & & & \\
\hline British Isles sample & 0.26 & {$[0.18,0.33]$} & 0.29 & {$[0.23,0.36]$} & 0.33 & {$[0.26,0.40]$} \\
\hline Chinese sample 1 & 0.20 & {$[0.12,0.28]$} & 0.28 & {$[0.22,0.35]$} & 0.36 & {$[0.29,0.44]$} \\
\hline Chinese sample 2 & 0.28 & {$[0.23,0.33]$} & 0.30 & {$[0.26,0.34]$} & 0.32 & {$[0.27,0.37]$} \\
\hline Chinese sample 3 & 0.23 & {$[0.16,0.30]$} & 0.28 & {$[0.22,0.34]$} & 0.33 & {$[0.27,0.40]$} \\
\hline Meta-analysis & 0.25 & {$[0.22,0.28]$} & 0.29 & {$[0.27,0.32]$} & 0.33 & {$[0.30,0.37]$} \\
\hline \multicolumn{6}{|l|}{ Honesty-Humility } & \\
\hline British Isles sample & 0.27 & {$[0.20,0.34]$} & 0.29 & {$[0.23,0.36]$} & 0.32 & {$[0.24,0.39]$} \\
\hline Chinese sample 1 & 0.16 & {$[0.08,0.24]$} & 0.28 & {$[0.22,0.35]$} & 0.41 & {$[0.33,0.48]$} \\
\hline Chinese sample 2 & 0.29 & {$[0.23,0.34]$} & 0.30 & {$[0.26,0.35]$} & 0.32 & {$[0.27,0.38]$} \\
\hline Chinese sample 3 & 0.22 & {$[0.15,0.29]$} & 0.28 & {$[0.22,0.34]$} & 0.34 & {$[0.27,0.41]$} \\
\hline Meta-analysis & 0.24 & {$[0.20,0.28]$} & 0.29 & {$[0.26,0.32]$} & 0.34 & {$[0.31,0.37]$} \\
\hline \multicolumn{7}{|l|}{ Openness to } \\
\hline \multicolumn{7}{|l|}{ Experience by } \\
\hline British Isles sample & 0.16 & {$[0.08,0.23]$} & 0.21 & {$[0.15,0.27]$} & 0.26 & {$[0.19,0.33]$} \\
\hline Chinese sample 1 & 0.07 & {$[-0.00,0.15]$} & 0.18 & {$[0.12,0.25]$} & 0.30 & {$[0.22,0.37]$} \\
\hline Chinese sample 2 & 0.13 & {$[0.08,0.18]$} & 0.19 & {$[0.15,0.23]$} & 0.26 & {$[0.21,0.30]$} \\
\hline Chinese sample 3 & 0.18 & {$[0.11,0.24]$} & 0.19 & {$[0.13,0.25]$} & 0.21 & {$[0.14,0.27]$} \\
\hline Meta-analysis & 0.14 & {$[0.10,0.17]$} & 0.19 & {$[0.17,0.22]$} & 0.25 & {$[0.22,0.28]$} \\
\hline \multicolumn{7}{|l|}{ Openness to } \\
\hline \multicolumn{7}{|l|}{ Experience by } \\
\hline British Isles sample & 0.14 & {$[0.07,0.21]$} & 0.21 & {$[0.14,0.27]$} & 0.28 & {$[0.20,0.35]$} \\
\hline Chinese sample 1 & 0.04 & {$[-0.03,0.12]$} & 0.19 & {$[0.13,0.25]$} & 0.34 & {$[0.26,0.42]$} \\
\hline Chinese sample 2 & 0.21 & {$[0.15,0.27]$} & 0.20 & {$[0.15,0.25]$} & 0.20 & {$[0.14,0.25]$} \\
\hline Chinese sample 3 & 0.17 & {$[0.10,0.23]$} & 0.19 & {$[0.13,0.25]$} & 0.22 & {$[0.15,0.29]$} \\
\hline Meta-analysis & 0.14 & {$[0.08,0.20]$} & 0.20 & {$[0.17,0.23]$} & 0.25 & {$[0.20,0.31]$} \\
\hline
\end{tabular}

Note. Meta-analytical estimates based on random effect models. $95 \%$ confidence intervals in brackets. 
DISTINCTIVE ASSUMED SIMILARITY IN HONESTY-HUMILITY AND OPENNESS TO EXPERIENCE

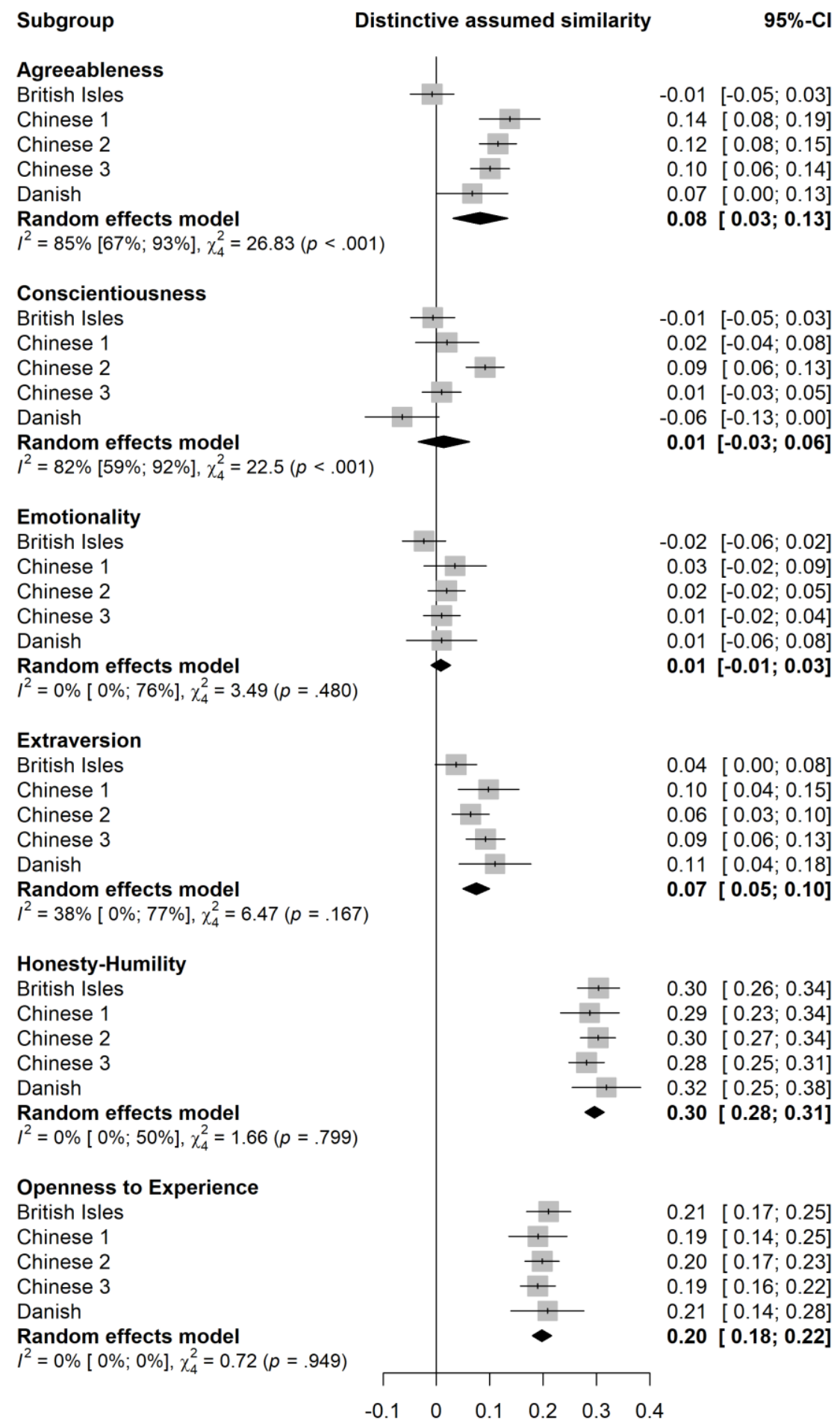

Figure 1. Distinctive assumed similarity in HEXACO trait 
DISTINCTIVE ASSUMED SIMILARITY IN HONESTY-HUMILITY AND OPENNESS TO EXPERIENCE

Subgroup

Honesty-Humility by Commitment

British Isles

Chinese 1

Chinese 2

Chinese 3

Random effects model

$I^{2}=81 \%[51 \% ; 93 \%], \chi_{3}^{2}=16.09(p=.001)$

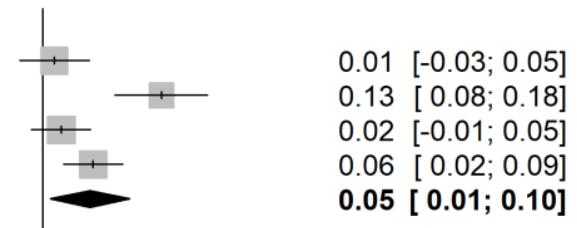

Honesty-Humility by Satisfaction

British Isles

Chinese 1

Chinese 2

Chinese 3

Random effects model

$I^{2}=54 \%[0 \% ; 85 \%], \chi_{3}^{2}=6.59(p=.086)$

Openness to Experience by Commitment

British Isles

Chinese 1

Chinese 2

Chinese 3

Random effects model

$I^{2}=89 \%[74 \% ; 95 \%], \chi_{3}^{2}=26.81(p<.001)$

Openness to Experience by Satisfaction

British Isles

Chinese 1

Chinese 2

Chinese 3

Random effects model

$I^{2}=76 \%[35 \% ; 91 \%], \chi_{3}^{2}=12.64(p=.005)$

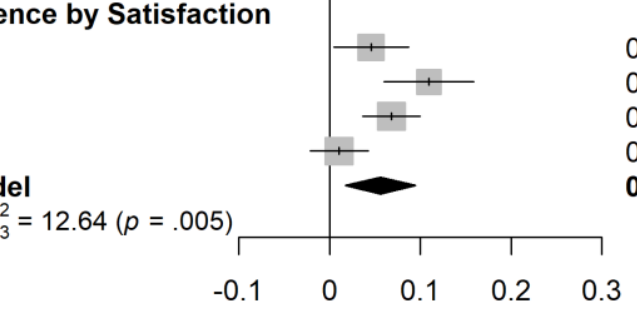

$0.03[-0.01 ; 0.06]$

$0.09[0.04 ; 0.14]$

$0.02[-0.01 ; 0.05]$

$0.05[0.02 ; 0.09]$

0.04 [ $0.02 ; 0.07]$

$0.06 \quad[0.02 ; 0.10]$

$0.15[0.10 ; 0.20]$

$-0.00[-0.04 ; 0.03]$

$0.03[-0.01 ; 0.06]$

$0.06[0.00 ; 0.11]$

$0.05[0.00 ; 0.09]$

$0.11[0.06 ; 0.16]$

0.07 [0.04;0.10]

$0.01[-0.02 ; 0.04]$

0.06 [ $0.02 ; 0.09$ ]

Figure 2. Association between relationship satisfaction, relationship commitment, and distinctive assumed similarity in Honesty-Humility and Openness to Experience 
DISTINCTIVE ASSUMED SIMILARITY IN HONESTY-HUMILITY AND OPENNESS TO EXPERIENCE

SUPPLEMENTARY MATERIALS

\begin{tabular}{|c|c|c|c|c|c|c|c|c|c|c|c|c|c|c|c|}
\hline \multicolumn{16}{|c|}{$\begin{array}{l}\text { Table } \mathrm{S} 1 \\
\text { Sample-specific results for distinctive assumed similarity }\end{array}$} \\
\hline & \multicolumn{3}{|c|}{ Danish } & \multicolumn{3}{|c|}{ British Isles } & \multicolumn{3}{|c|}{ Chinese 1} & \multicolumn{3}{|c|}{ Chinese 2} & \multicolumn{3}{|c|}{ Chinese 3} \\
\hline & est & SE & $p$ & est & SE & $p$ & est & SE & $p$ & est & SE & $p$ & est & SE & $p$ \\
\hline Profile & 0.11 & 0.02 & $<.001$ & 0.09 & 0.01 & $<.001$ & 0.13 & 0.02 & $<.001$ & 0.14 & 0.01 & $<.001$ & 0.12 & 0.01 & $<.001$ \\
\hline $\mathrm{AG}$ & 0.07 & 0.03 & .050 & -0.01 & 0.02 & .696 & 0.14 & 0.03 & $<.001$ & 0.12 & 0.02 & $<.001$ & 0.10 & 0.02 & $<.001$ \\
\hline $\mathrm{CO}$ & -0.06 & 0.04 & .069 & -0.01 & 0.02 & .744 & 0.02 & 0.03 & .511 & 0.09 & 0.02 & $<.001$ & 0.01 & 0.02 & .600 \\
\hline EM & 0.01 & 0.03 & .774 & -0.02 & 0.02 & .263 & 0.03 & 0.03 & .244 & 0.02 & 0.02 & .280 & 0.01 & 0.02 & .572 \\
\hline EX & 0.11 & 0.03 & .002 & 0.04 & 0.02 & .067 & 0.10 & 0.03 & $<.001$ & 0.06 & 0.02 & $<.001$ & 0.09 & 0.02 & $<.001$ \\
\hline $\mathrm{HH}$ & 0.32 & 0.03 & $<.001$ & 0.30 & 0.02 & $<.001$ & 0.29 & 0.03 & $<.001$ & 0.30 & 0.02 & $<.001$ & 0.28 & 0.02 & $<.001$ \\
\hline $\mathrm{OE}$ & 0.21 & 0.04 & $<.001$ & 0.21 & 0.02 & $<.001$ & 0.19 & 0.03 & $<.001$ & 0.20 & 0.02 & $<.001$ & 0.19 & 0.02 & $<.001$ \\
\hline
\end{tabular}


DISTINCTIVE ASSUMED SIMILARITY IN HONESTY-HUMILITY AND OPENNESS TO EXPERIENCE

Table S2

Sample-specific results for distinctive assumed similarity moderated by relationship satisfaction

\begin{tabular}{|c|c|c|c|c|c|c|c|c|c|c|c|c|}
\hline & \multicolumn{3}{|c|}{ British Isles } & \multicolumn{3}{|c|}{ Chinese 1} & \multicolumn{3}{|c|}{ Chinese 2} & \multicolumn{3}{|c|}{ Chinese 3} \\
\hline & est & SE & $p$ & est & $\mathrm{SE}$ & $p$ & est & $\mathrm{SE}$ & $p$ & est & $\mathrm{SE}$ & $p$ \\
\hline Profile & 0.05 & 0.01 & $<.001$ & 0.08 & 0.02 & $<.001$ & 0.03 & 0.01 & .020 & 0.04 & 0.01 & $<.001$ \\
\hline $\mathrm{AG}$ & 0.06 & 0.02 & .003 & 0.14 & 0.03 & $<.001$ & -0.03 & 0.02 & .123 & 0.11 & 0.02 & $<.001$ \\
\hline $\mathrm{CO}$ & 0.00 & 0.02 & .865 & 0.08 & 0.03 & .005 & 0.03 & 0.02 & .115 & 0.01 & 0.02 & .453 \\
\hline EM & 0.04 & 0.02 & .063 & -0.00 & 0.03 & .950 & 0.01 & 0.02 & .544 & 0.04 & 0.02 & .024 \\
\hline $\mathrm{EX}$ & 0.08 & 0.02 & $<.001$ & 0.05 & 0.03 & .045 & 0.01 & 0.02 & .454 & 0.02 & 0.02 & .387 \\
\hline $\mathrm{HH}$ & 0.03 & 0.02 & .190 & 0.09 & 0.03 & $<.001$ & 0.02 & 0.02 & .170 & 0.05 & 0.02 & .001 \\
\hline $\mathrm{OE}$ & 0.05 & 0.02 & .031 & 0.11 & 0.03 & $<.001$ & 0.07 & 0.02 & $<.001$ & 0.01 & 0.02 & .532 \\
\hline
\end{tabular}

Note. $\mathrm{AG}=$ Agreeableness. $\mathrm{CO}=$ Conscientiousness. $\mathrm{EM}=$ Emotionality. $\mathrm{EX}=$ Extraversion. $\mathrm{HH}=$ Honesty-Humility. OE $=$ Openness to Experience 
DISTINCTIVE ASSUMED SIMILARITY IN HONESTY-HUMILITY AND OPENNESS TO EXPERIENCE

Table S3

Sample-specific results for distinctive assumed similarity moderated by relationship commitment

\begin{tabular}{|c|c|c|c|c|c|c|c|c|c|c|c|c|}
\hline & \multicolumn{3}{|c|}{ British Isles } & \multicolumn{3}{|c|}{ Chinese 1} & \multicolumn{3}{|c|}{ Chinese 2} & \multicolumn{3}{|c|}{ Chinese 3} \\
\hline & est & $\mathrm{SE}$ & $p$ & est & $\mathrm{SE}$ & $p$ & est & SE & $p$ & est & $\mathrm{SE}$ & $p$ \\
\hline Profile & 0.04 & 0.01 & .001 & 0.07 & 0.02 & $<.001$ & 0.01 & 0.01 & .440 & 0.04 & 0.01 & $<.001$ \\
\hline $\mathrm{AG}$ & 0.04 & 0.02 & .033 & 0.07 & 0.03 & .012 & -0.06 & 0.02 & .002 & 0.06 & 0.02 & $<.001$ \\
\hline $\mathrm{CO}$ & 0.01 & 0.02 & .600 & 0.06 & 0.03 & .047 & 0.03 & 0.02 & .051 & 0.03 & 0.02 & .078 \\
\hline EM & 0.05 & 0.02 & .016 & -0.03 & 0.03 & .338 & 0.01 & 0.02 & .435 & 0.04 & 0.02 & .020 \\
\hline EX & 0.05 & 0.02 & .022 & -0.01 & 0.03 & .658 & 0.02 & 0.02 & .191 & 0.02 & 0.02 & .192 \\
\hline $\mathrm{HH}$ & 0.01 & 0.02 & .509 & 0.13 & 0.03 & $<.001$ & 0.02 & 0.02 & .227 & 0.06 & 0.02 & $<.001$ \\
\hline $\mathrm{OE}$ & 0.06 & 0.02 & .002 & 0.15 & 0.03 & $<.001$ & -0.00 & 0.02 & .821 & 0.03 & 0.02 & .124 \\
\hline
\end{tabular}

Note. $\mathrm{AG}=$ Agreeableness. $\mathrm{CO}=$ Conscientiousness. $\mathrm{EM}=$ Emotionality. EX $=$ Extraversion. $\mathrm{HH}=\mathrm{Honesty}-\mathrm{Humility} . \mathrm{OE}=\mathrm{Openness}$ to Experience 
DISTINCTIVE ASSUMED SIMILARITY IN HONESTY-HUMILITY AND OPENNESS TO EXPERIENCE

Table S4

$\frac{\text { Results for distinctive actual similarity in Chinese } 3 \text { sample }}{\text { Main effects } \quad \text { Moderation by relationship }}$

$\frac{\text { Results for distinctive actual similarity in Chinese } 3 \text { sample }}{\text { Main effects }}$ satisfaction

Moderation by relationship commitment

\begin{tabular}{|c|c|c|c|c|c|c|c|c|c|}
\hline & est & SE & $p$ & est & SE & $p$ & est & $\mathrm{SE}$ & $p$ \\
\hline Profile & 0.02 & 0.01 & .003 & -0.00 & 0.01 & .904 & 0.01 & 0.01 & .375 \\
\hline $\mathrm{AG}$ & 0.00 & 0.02 & .805 & 0.01 & 0.02 & .625 & 0.01 & 0.02 & .591 \\
\hline $\mathrm{CO}$ & 0.03 & 0.02 & .065 & -0.03 & 0.02 & .090 & 0.00 & 0.02 & .936 \\
\hline EM & -0.00 & 0.02 & .842 & -0.01 & 0.02 & .572 & -0.01 & 0.02 & .352 \\
\hline EX & 0.04 & 0.02 & .032 & 0.02 & 0.02 & .300 & 0.01 & 0.02 & .556 \\
\hline $\mathrm{HH}$ & 0.04 & 0.02 & .004 & 0.01 & 0.02 & .553 & 0.04 & 0.02 & .004 \\
\hline $\mathrm{OE}$ & 0.02 & 0.02 & .114 & 0.00 & 0.02 & .854 & -0.01 & 0.02 & .678 \\
\hline
\end{tabular}

Note. $\mathrm{AG}=$ Agreeableness. $\mathrm{CO}=$ Conscientiousness. $\mathrm{EM}=$ Emotionality. $\mathrm{EX}=$ Extraversion. $\mathrm{HH}=$ Honesty-Humility. $\mathrm{OE}=\mathrm{Openness}$ to Experience 
DISTINCTIVE ASSUMED SIMILARITY IN HONESTY-HUMILITY AND OPENNESS TO EXPERIENCE

Table S5

Assumed similarity correlations for trait scale aggregates

\begin{tabular}{|c|c|c|c|c|c|c|c|c|c|c|c|c|c|c|c|c|c|c|}
\hline & \multicolumn{3}{|c|}{ Danish } & \multicolumn{3}{|c|}{ British Isles } & \multicolumn{3}{|c|}{ Chinese 1} & \multicolumn{3}{|c|}{ Chinese 2} & \multicolumn{3}{|c|}{ Chinese 3} & \multicolumn{3}{|c|}{ Meta-analysis } \\
\hline & $r$ & SE & $p$ & $r$ & SE & $p$ & $r$ & SE & $p$ & $r$ & SE & $p$ & $r$ & SE & $p$ & $r$ & SE & $p$ \\
\hline $\mathrm{AG}$ & -.02 & 0.11 & .877 & -.10 & 0.06 & .094 & .21 & 0.08 & .014 & .12 & 0.05 & .024 & .13 & 0.06 & .026 & .07 & 0.05 & .164 \\
\hline $\mathrm{CO}$ & -.20 & 0.10 & .053 & -.03 & 0.06 & .617 & -.04 & 0.08 & .637 & .16 & 0.05 & .002 & -.05 & 0.06 & .361 & -.01 & 0.05 & .786 \\
\hline EM & -.18 & 0.10 & .087 & -.20 & 0.06 & .001 & .02 & 0.08 & .847 & -.13 & 0.05 & .012 & -.15 & 0.06 & .006 & -.14 & 0.03 & $<.001$ \\
\hline EX & .16 & 0.10 & .123 & .02 & 0.06 & .755 & .08 & 0.08 & .327 & .07 & 0.05 & .187 & .08 & 0.06 & .155 & .07 & 0.03 & .018 \\
\hline $\mathrm{HH}$ & .50 & 0.09 & $<.001$ & .44 & 0.05 & $<.001$ & .49 & 0.07 & $<.001$ & .52 & 0.05 & $<.001$ & .48 & 0.05 & $<.001$ & .53 & 0.03 & $<.001$ \\
\hline $\mathrm{OE}$ & .35 & 0.10 & $<.001$ & .31 & 0.06 & $<.001$ & .26 & 0.08 & .002 & .27 & 0.05 & $<.001$ & .30 & 0.05 & $<.001$ & .30 & 0.03 & $<.001$ \\
\hline
\end{tabular}

Note. $\mathrm{AG}=$ Agreeableness. $\mathrm{CO}=$ Conscientiousness. $\mathrm{EM}=$ Emotionality. $\mathrm{EX}=$ Extraversion. $\mathrm{HH}=\mathrm{Honesty}-\mathrm{Humility} . \mathrm{OE}=\mathrm{Openness}$ to Experience. Random effect maximum likelihood estimates for meta-analysis. 